\title{
INVESTIGATION OF DISCHARGE AND SEDIMENTATION RATES OF THE SEFID-ROUD RIVER AFTER DE-SILTATION OF THE SEFID-ROUD DAM, IRAN
}

\author{
SEYED AHMAD NESHAEI ${ }^{1}$, MIR ABDOLHAMID MEHRDAD ${ }^{1} \&$ SEYED HOSSEIN MOLATEFAT $^{2}$ \\ ${ }^{1}$ Department of Civil Engineering, University of Guilan, Iran \\ ${ }^{2}$ Department of Civil Engineering, University of Jahad Daneshgahi Guilan, Iran
}

\begin{abstract}
The Sefid-roud river is located in the Guilan province in the northern part of Iran and in the vicinity of the southern coastal region of the Caspian Sea. In recent years, due to a lack of watershed process and some geological reasons, a large amount of sediments have arrived in the Sefid-roud reservoir. Moreover, the measured bed and suspended loads are much greater than the estimated figures. These are the major reasons for the declining the life of the Sefid-roud dam due to high rate of sediment deposition. Nowadays, de-siltation of dam reservoirs by regressive erosion is a new method that works efficiently by water hydrodynamic power against sediments in dam reservoirs. In this method, following the construction of an erosional channel in the sediment deposit area ending by a drop to create the high shear stress super critical flow, the mechanism of regressive erosion causes the huge amount of sediments to be moved downward. This paper contains a review of the mechanisms of sedimentation in storage reservoirs; the result of theoretical and experimental investigations in the Sefid-roud dam using a mathematical model estimates the amount of sediments and the effect of different parameters in the mentioned method. Some complementary measures have been introduced to increase the de-siltation efficiency of flushing operations based of field observation and experiments made during the de-sedimentation operation of the Sefid-roud reservoir. The rate of sediment to discharge for different years is evaluated and plotted to indicate the behavior of the Sefid-roud river during recent years.
\end{abstract}

Keywords: flushing, dam, reservoir, regressive erosion, shear stress, channel bed, Sefid-roud river.

\section{INTRODUCTION}

Deposits in dam's reservoirs have negative effects on production of hydroelectricity and farmlands irrigation, in addition to severe reduction of reservoir volume. Damages on dam installations such as penstocks, turbines, etc. are the results of deposits movement toward penstocks and passage of the abrasive particles from inside the penstocks. Accumulation of deposits in dam reservoirs due to high water depth causes a very high density and viscosity of particles, so then, it is difficult to take deposits out of reservoir for recycling its capacity; therefore, it requires high expenses and pause in exploitation of dams so the cost of reservoir volume recycling loss equals to or is more than a new dam construction [1]. Flushing operation is a successful method in flushing the dam reservoir. In this method, when the lower penstocks are opened and reservoir water is discharged, the accumulated deposits in the reservoir are transferred to the downstream through eroded penstocks in dam's upstream [2]. The closer the accumulated deposits in the dam reservoir to the lower penstocks and the less stabilized the deposits, the higher the efficiency of deposit flushing. Flushing complementary operations have been executed in Sefid-roud (Ghezel Ozon bank) and Tarik dams recently and in Shahrood bank of Sefid-roud Dam in 1988 [3]. With regard to very good performance and cost effectiveness, execution of this method leads to acceptable results in comparison to other methods. The present study tries to compare practical and theoretical results with each other by presenting theoretical basis for regressive erosion mechanism. 


\section{FLUSHING COMPLEMENTARY OPERATIONS}

Flushing complementary operations are executed by creating embankment in inlet top branches to the reservoirs and increasing water digits behind embankment and constructing a channel in deposited terrace from embankment site to the lower penstocks and channel docking. This causes increase in longitudinal slope of the channel and finally shear stress increase leads to flow velocity increase and causes to flush more deposits. When channel discharge increases, erosion starts with the end of channel and expands upward. When this happens, deposits are transferred to the dam location with water flow. Since there is no theoretical basis for this method as well as the calculation of regressive erosion, we intended to present a method for calculation of the deposits transferred from these operations and a comparison between practical and theoretical results in order to assess efficiency of this method. Of course, due to difference in erosion mechanism in the viscous and non-viscous deposits, they are studied separately.

\subsection{Regressive erosion mathematical model in non-viscous deposits}

When shear stress increases in the bed and channel wall exceeding the permissible limit, the flushed deposits, width, and depth of the primary channel, are gradually increased and are transferred to the downstream. In non-viscous deposits, channel is widened due to erosion of cross section and slip and fall are negligible in the wall. If the drilled channel cross section inside the deposited terrace is assumed to be trapezoid and with floor width of $\mathrm{B}$, height of $\mathrm{H}$ and slope of wall are assumed to be 1 vertical to horizontal $\mathrm{Z}$, the discharge of diversion channel cross section can be calculated by the Manning equation [4]:

$$
Q=\frac{1}{n} A R^{2 / 3} S_{0}^{1 / 2}
$$

Roughness coefficient of eroded channel can be calculated through eqn (2) with regard to average diameter of deposited particles of channel bed:

$$
n=\frac{d_{50} 1 / 6}{21.1},
$$

where $\mathrm{S}$ is longitudinal slope and AR is hydraulic radius and channel cross section.

Water velocity in channel is calculated from the following equation:

$$
V=\frac{Q}{A}
$$

Therefore, we have flow regime in channel with use of Froude Number as follows [4]:

$$
F r=\frac{V}{\sqrt{g D}},
$$

where $\mathrm{D}$ is hydraulic depth of the channel cross section.

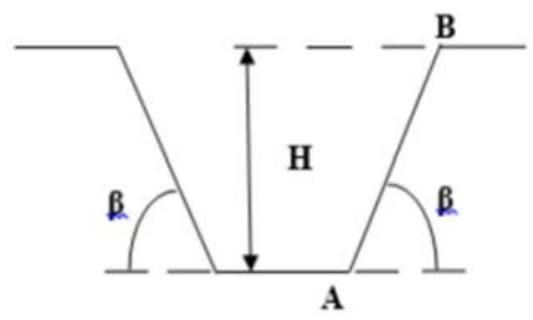

Figure 1: Hypothetical channel section. 
When flow velocity increases due to flood or water release from the reservoir behind the diversion dam, Froude number increases and flow is converted from subcritical to supercritical and bed erosion risk will then be increased. Regarding the fact that, flow velocity increment beyond the permissible velocity depends on physical characteristics of the deposited particles (including particle size, angle of repose, particle shape, settling velocity), we can recognize the major factor of deposits motion in deposited terrace, as shear stress increases, in channel cross section beyond the permissible value. Shear stress in floor of a wide channel can be determined from the following equation [4]:

$$
\tau_{0}=\gamma R S_{\circ}
$$

where $\gamma$ is specific weight of water, $\mathrm{R}$ is hydraulic radius of channel cross section and $\mathrm{S}$ is longitudinal slope of channel. In this equation, shear stress value is determined in wall of the channel from the following equation [5]:

$$
\frac{\tau}{\tau_{0}}=\sqrt{1-\frac{\sin ^{2} \phi}{\sin ^{2} \theta}},
$$

where $\phi$ is internal friction angle of the materials constituting channel bed and $\theta$ is channel wall slope angle. However, shear stress value of the channel wall is obtained with good approximation of 0.75 of shear stress of the channel floor. But permissible shear stress of the bed is subject to material and granulation of the terrace and may be obtained by different methods. Eqn (7) is one of the equations with which we can calculate the permissible shear stress of the non-viscous bed [5]:

$$
\tau_{0} \approx 0.078 d_{75},
$$

where $d_{75}$ can be calculated based on bed particles granulation curve in mm. One of the equations for calculation of permissible shear stress for granular soils is presented below [3].

$$
\begin{aligned}
& d_{50}>0.006 \mathrm{~m} \rightarrow \tau_{0 c r}=0.076\left(\gamma_{s}-\gamma\right) d_{50} \\
& 0.001<d_{50}<0.003 \mathrm{~m} \\
& \rightarrow \tau_{0 c r}=0.000285\left(\gamma_{s}-\gamma\right) d_{50}{ }^{1 / 3} \\
& \tau_{0 c r}=\sqrt{0.201 \gamma\left(\gamma_{s}-\gamma\right) \lambda d_{50}{ }^{3}}
\end{aligned}
$$

In this equation, $\lambda$ was considered to be 1 for spherical particles, 1 and 4.4 for flat and disk shaped deposited particles and is obtained from the following equation:

$$
\lambda=\sqrt{\frac{c}{a b}}
$$

Another equation has been presented for calculation of permissible shear stress based on Toloei equations (1993) on the basis of experience of Shahrood diversion channel in Sefidrood dam reservoir which has been shown in eqns (10) and (11) [3].

For consolidated non-viscous deposits (sediment-sand granulation):

$$
\begin{aligned}
& \tau_{0 c}=0.052\left(\rho_{s}-\rho_{f}\right) \\
& g d_{50}\left[1+I_{p}{ }^{0.9}+\rho_{s c}{ }^{0.84} \log (9+T)\right]
\end{aligned}
$$

For unconsolidated viscous deposits (sediment-sand granulation):

$$
\tau_{0 C}=4 L i^{-1.25}[\log (9+T)]^{0.5}
$$

In the above equation: 
$\rho_{f}, \rho_{s}$ equals to density of the deposit and water.

$d_{50}$ equals to average diameter of deposit grains in $\mathrm{mm}$.

$I_{P}$ equals to plasticity index in percentage.

$\rho_{S C}$ equals to percentage of sediment and clay grains in deposits.

$\mathrm{T}$ equals to age of deposits in reservoir.

$\mathrm{Li}$ equals to ratio of natural humidity to fluidity of deposits.

$\tau_{0 C}$ equals to shear stress of deposits in Newton / sq. meter.

Another method of finding permissible shear stress with regard to viscosity or nonviscosity of soil is to use shields diagram Fig. 2 or modified shields diagram Fig. 3 [5].

The maximum permissible velocity of the bed is obtained from eqns (12) and (13) [6] or deposit hydraulic tables with regard to non-erosion.

For granular soils:

$$
V_{\max }=3\left(\frac{d_{50}}{d_{\max }}\right)^{0.2} y^{0.5}\left(d_{50}+0.0014\right)^{0.3}
$$

For viscous soils:

$$
V_{\max }=K R^{\frac{1}{2+R}}
$$

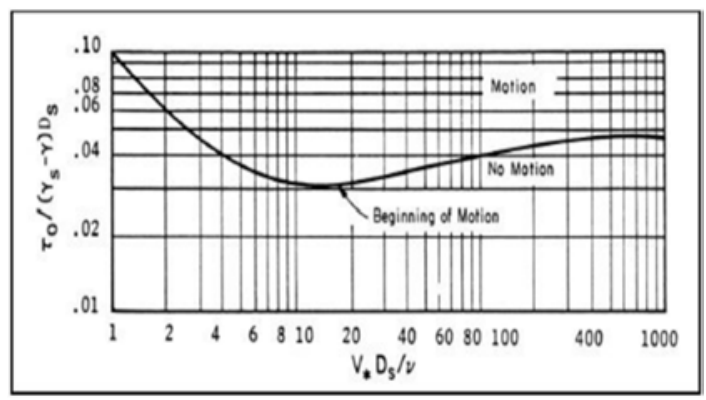

Figure 2: Critical Shields stress diagram.

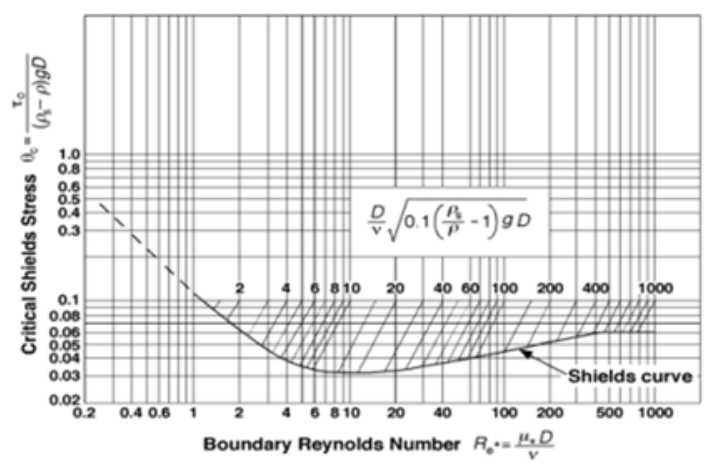

Figure 3: Modified Shields diagram. 
In these equations:

$\mathrm{d}_{\max }$ is the maximum diameter of deposited grains in water.

$\mathrm{Y}$ is depth of water in channel.

$\mathrm{R}$ is hydraulic radius of channel cross section.

$\mathrm{K}$ is bed soil density function coefficient which is considered to be $0.4-0.6$ in non-dense soils and $0.8-0.9$ in dense soils.

In this regard, when discharge increases and flow increases, erosion energy in a static channel is increased and shear stress applied on the channel wall exceeds permissible shear stress of the constituent material and balance is kept for increasing the cross sections dimensions and longitudinal slope of the channel. Concerning this result, weight discharge of the flushed deposits from the channel is calculated from eqns (14), (15) and (16) [6].

Shields equation:

$$
\frac{g_{s}}{\gamma \cdot q} \times \frac{\gamma_{s}-\gamma}{s . \gamma}=10 \frac{\tau_{o}-\tau_{\text {ocr }}}{\left(\gamma_{s}-\gamma\right) d}
$$

Gilbert equation:

$$
\begin{gathered}
g_{s}=\frac{7000}{d^{1 / 2}} S_{\circ}^{3 / 2}\left(q-q_{c r}\right) \\
q_{c r}=\frac{1.944 \times 10^{-5} d}{S_{\circ}^{4 / 3}}
\end{gathered}
$$

Schoklitsch equation:

$$
\begin{aligned}
& g_{s}=2500 S_{\circ}^{3 / 2}\left(q-q_{c r}\right) \\
& q_{c r}=0.26\left(\frac{\gamma_{s}-\gamma}{\gamma}\right)^{5 / 3} \frac{d^{3 / 2}}{S_{\circ}^{7 / 6}}
\end{aligned}
$$

In the above equations, $g_{s}$ is weight of the transferred deposits in channel width unit and in time unit (weight discharge of bed solid material) and $\gamma_{s}, \gamma$ are specific weight of water and deposits respectively and $S_{\text {。 }}$ is longitudinal slope of the channel. Therefore, one may approximately estimate ratio of diversion channel widening and regressive erosion with time, concerning the above equations. It is worth noting that, use of these equations leads to high approximation with regard to complex texture of deposited particles in dam reservoir and changes of granulation curve and mechanical specifications of deposits such as internal friction angle, viscosity and specific weight of deposits. However, these equations may indicate the outcome of regressive erosion and its changes in time.

\subsection{Regressive erosion mathematical model in viscous deposits}

Erosion mechanism in viscous deposits is different from non-viscous deposits and the performed research on such deposits is more limited than non-viscous deposits. Generally speaking, erosion occurs in viscous deposits either as mass in bed surface or particle. In viscous deposits, when shear stress of $\tau_{b}$ bed exceeds critical value of $\tau_{e}$, erosion will occur. This process depends on different parameters such as, mineral compounds, organic material density and other parameters of deposit and bed structure. On the basis of the performed research, critical stress of the floor for erosion depends on deposition and history of deposits 
consolidation. All available information about consolidated deposits is based on date analysis resulting from small natural channels. Critical shear stress can be obtained from Toloei eqns (10) and (11) [3] and this value can relate to drained deposit density and expressed according to eqn (17) [7].

$$
\tau_{e}=\alpha\left(\rho_{d r y}\right)^{\beta}
$$

$\beta$ Coefficient was obtained to be between 1 and 2.5 according to the performed research and different persons have obtained this coefficient for different cases. Julien [5] obtained $\beta$ value to be 1.5 for Bris Bane River as well as Scotland and Indonesia rivers. Bart (1990) obtained value of $\beta$ to be 1.5 in England. In Netherlands, this coefficient equals to 1.5 however $\alpha$ coefficient is smaller than or equals to 1 . By considering a channel with height of $\mathrm{H}$ and side slope of $\beta$ as follows at the beginning of channel docking and in $\Delta t$, depth of channel increases from $\mathrm{H}$ to $H^{\prime}$ and this is due to erosion of channel bed which is obtained from eqn (18) [7]:

$$
d m=M\left[\frac{\tau_{b}-\tau_{e}}{\tau_{e}}\right] \times d t,
$$

where $\tau_{b}$ is shear stress and $\tau_{e}$ is obtained from eqn (17).

By obtaining dm and dividing it by deposit density, deposit volume is obtained and $H^{\prime}$ can be obtained. The main difference of regressive erosion mathematical model in viscous deposits and non-viscous deposits is mass slide and fall in the walls and this value can be excluded in non-viscous deposits. In this case, it seems that slide and fall of walls, follow slope stability theory with regard to observations and obtained experiences. Meanwhile, Colman method may be a suitable method for the related state due to high conformity with conditions and regarding the fact that viscosity and internal friction angle of the soil have been used and its surface of rupture was considered to be flat. Therefore, for a slope with height of $\mathrm{H}$ and gradient of $\beta$, critical value $\theta$ is obtained with respect to weight of failure wedge and from the following equation [8]:

$$
\theta_{c r}=\frac{\beta+\phi}{2}
$$

$\mathrm{BC}$ and triangle surface of $\mathrm{ABC}$ will be obtained from the equations below [8]:

$$
\begin{gathered}
B C=\frac{H}{\sin \beta} \times \frac{\sin \left(\frac{\beta-\phi}{2}\right)}{\sin \left(\frac{\beta+\phi}{2}\right)} \\
S_{A B C}=\frac{H^{2}}{2 \sin \beta} \times \frac{\sin \left(\frac{\beta-\phi}{2}\right)}{\sin \left(\frac{\beta+\phi}{2}\right)}
\end{gathered}
$$

In Figs 5, 6 and 7, deposit volume changes diagram is shown with specific weight changes and friction angle and longitudinal slope of channel. Critical height for slope slide is not very important for us because some factors such as toe erosion and shear stress on walls resulting from water flow helps slide of slopes and critical height for slide and fall will be lower than 
the calculated value in this method. Therefore, with regard to Fig. 8, we consider channel walls slide model in such a manner that when height of channel reaches $H^{\prime}$,walls will fall at the end of the first-time interval $\Delta t$ and two $\mathrm{S}$ surfaces will collapse from wall of the channel.

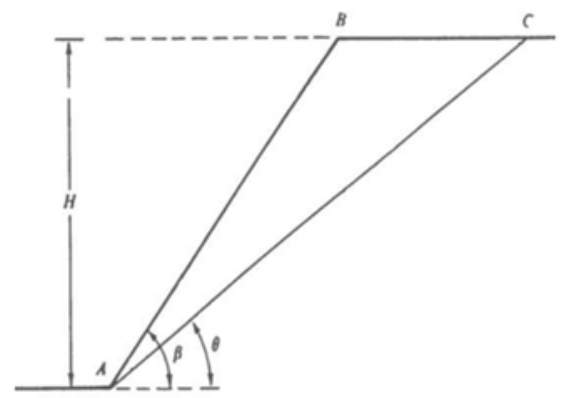

Figure 4: Gable roof Culmann method.

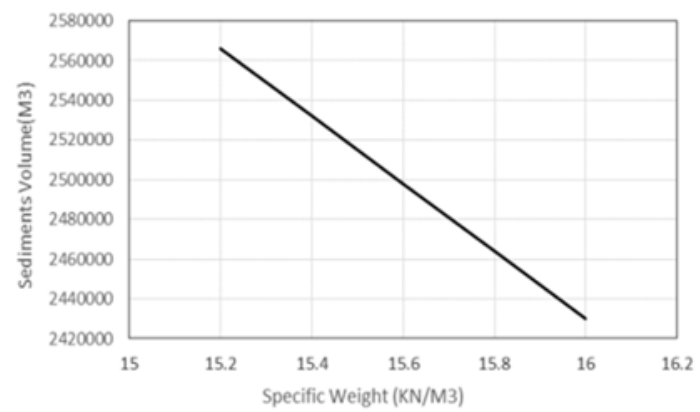

Figure 5: Displaced deposit volume changes diagram with changes of deposits specific weight.

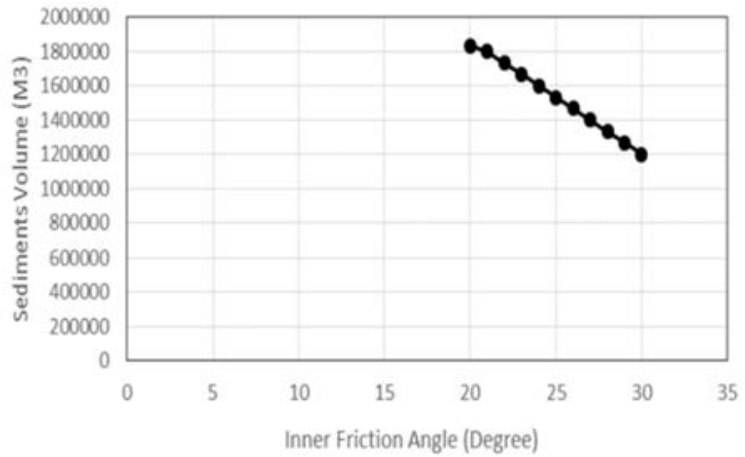

Figure 6: Inner friction angle changes with Sediments volume diagram. 


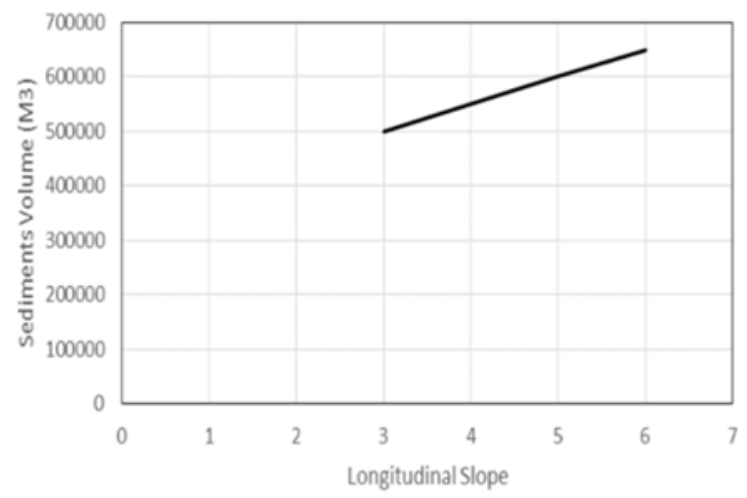

Figure 7: Sediments volume changes with longitudinal slope.

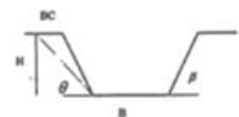

a) Initial Canal Section

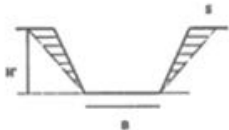

c) Walls Falling

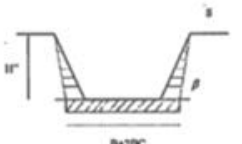

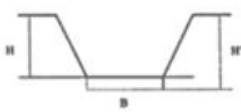

b) Bed Abrasion

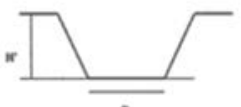

d) Canal Section After Walls Falling

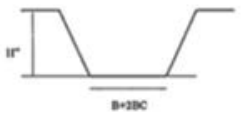

e) Bed And Wall Abrasion (Second Time) e) Final Canal Section Before Second Falling

Figure 8: Failing and abrasion in walls.

In the second-time interval, erosion occurs in walls, so that, angle of wall reaches $\beta$. Erosion occurs in the bed concurrently with erosion of walls and height of channel reaches $H^{\prime \prime}$. Finally, the new cross section with width of $\mathrm{B}+2 \mathrm{BC}$ and height of $H^{\prime \prime}$ becomes ready to represent fall of walls and so will be repeated in each time interval.

\section{CASE STUDY}

\subsection{Sefid-roud Dam}

Sefid-roud Dam is made from concrete with backfill with maximum height of $106 \mathrm{~m}$, crest length of $425 \mathrm{~m}$, and primary volume of 1760 million cubic meters. Dam dischargers include two surfaces overflows with total flow of 3000 cubic meters/s and two half-deep dischargers 
with discharge flow of 2000 cubic meters /s, as well as deep discharger with discharge flow of 980 cubic meters and 5 power plant ponds with discharge flow of 160 cubic meters/s [8]. In 2000, complementary flushing operations project was performed on a trapezoid channel section with a length of $5 \mathrm{~km}$ and surface of 12 cubic meters in the left shore. Excavation volume of this channel was 80000 cubic meters with longitudinal slope of 0.003 . In October 2001, an earth dam was designed with height of $17 \mathrm{~m}$ and wall slope of 1.5 to 1 in mirage and 2 to 1 ford with use of material available in a reservoir including sand, gravel, rubble, and armor stones. This dam was constructed in Shore of Ghezel Ozan River $1 \mathrm{~km}$ away from channel site. The earth dam with a crest length of $200 \mathrm{~m}$ caused to have a capacity of 10 million cubic meters, so the volume of required material for this earth dam was estimated to be 65000 cubic meters. The maximum flow of this dam in digits of 253.79 water level with mirage of $20.637 \mathrm{l} / \mathrm{s}$ and the minimum flow in digits 250.62 is $1.062 \mathrm{l} / \mathrm{s}$. Docking in the channel started on 18 Nov. 2001 with flow of 0.5 cubic $\mathrm{m} / \mathrm{s}$ and increased to 2 cubic meters /s on 20 Nov. 2001 so that it reached about 70 cubic m/s after two days. After 1 month and due to entrance of flood water flows of 80 cubic meters/s and suitable speed of the flow at the end of the channel and spillage of walls and creation of different waterfalls, regressive state in the channel caused an increase in depth and widened the channel.

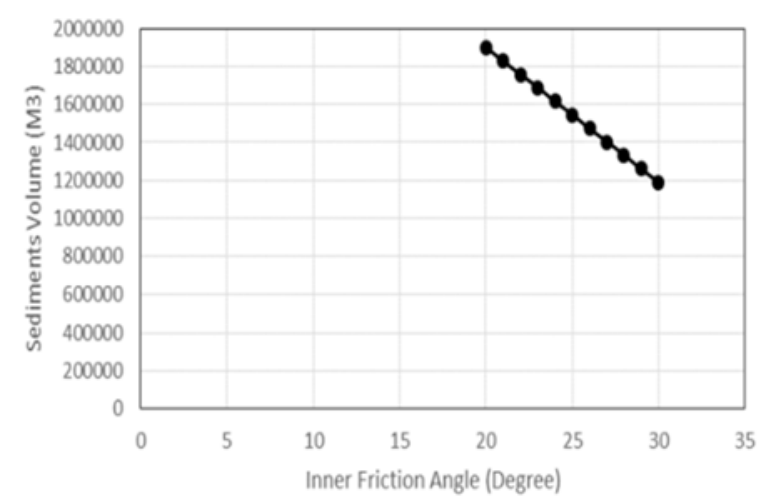

Figure 9: Inner friction angle changes with sediments volume diagram.

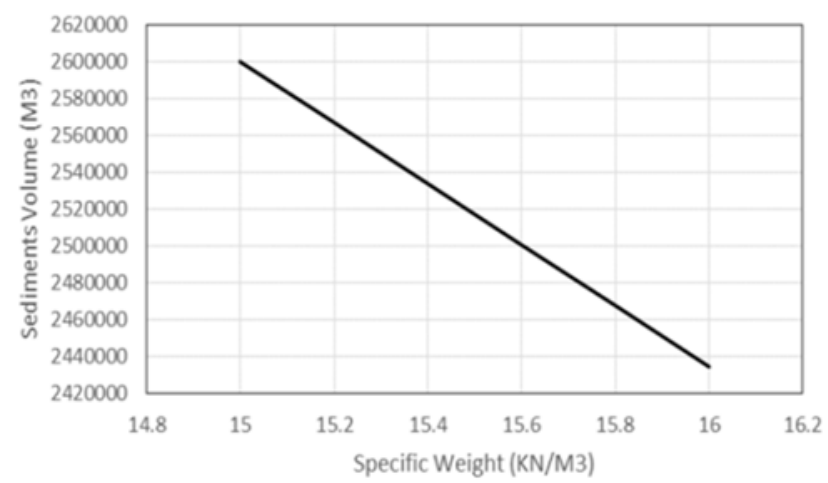

Figure 10: Specific weight changes with sediments volume diagram. 


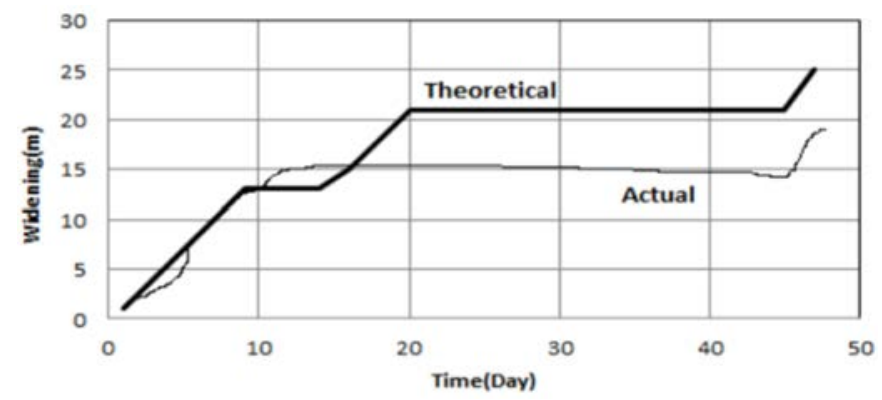

Figure 11: Comparison the theoretical and actual widening of the channel.

With the use of a prepared computer program relating to the viscous deposits to calculate the transferred volume in Sefid-roud Dam reservoir as a result of execution of flushing operations, deposit volume for this case was found to be 2600000 cubic meters. In this case, results of surveying operations on the reservoir deposit terrace and in channel indicate displacement of 3000000 cubic meters of the deposit which is satisfactory concerning the results obtained from computer calculations. Figs 9 and 10 show the effect of two parameters of specific weight and internal friction angle on volume of the displaced deposit. We may conclude from these figures that specific weight and internal friction angle are reversely related to volume of deposit. There is a good march between these two figures and the prepared computer program. Fig. 11 shows that channel widening in terms of time and channel widening, follows rate-time curve at most times and rate increase which causes to widen the channel. This indicates, different layering with different densities, because, erosion stops temporarily during regressive erosion of channel when this erosion collides with a hard layer and erosion starts again when wall of the channel and channel bed disappear. In the following figure, there is comparison between theoretical and actual values of channel section widening and the two values indicate equal trend.

\section{FLUSHING COMPLEMENTARY OPERATIONS EFFICIENCY INCREASE METHODS}

In order to increase efficiency of flushing commentary operations, the following methods are able to work desirably.

\subsection{Injection sinks}

Soil is a solid set of the composed particles, so that, there are pores for the water to pass a high energy point to a low energy point. Water moves toward these pores with speed dependent on hydraulic gradient and material permeability. In this case, particles are gradually washed due to time piping and local hydraulic gradient causes zero effective stress in the permeable material. Critical hydraulic permeability can be 1 for upward flows and can be less for downward flows. What seems proper is that injection sinks drilling within 40 to $50 \mathrm{~m}$ of channel causes to increase velocity of the channel erosion and deposits will be transferred with higher efficiency whether in terms of volume or velocity. In this regard, this method has been tested in 1987 (before execution of the flushing complementary operations project) in order to recognize the problem scientifically and to find effective factors for creating the above phenomenon and confirm the subject scientifically through flushing project executives in Sefid-roud Dam Reservoir. In the first phase, positive result was 
achieved by drilling hand well with depth of $4 \mathrm{~m}$ and water pumping into it with the use of simple tools, so that, gully with length of $4 \mathrm{~m}$ and depth of $6 \mathrm{~m}$ within 15 days of alternate pumping with flow of 3 liters per second. On this basis, we may guess that if the grouting wells construction project was executed near erosion channel and water was pumped inside them, return of the performed operation might be increased.

\subsection{Making channel walls unstable}

As explained in the "mathematical model of regressive erosion in viscous sediments", wall slide model was based on stability of gables. According to the observation and the performed studies, slide of walls occurs in two forms as shown in Fig. 12 for the consolidated clays and un consolidated clays. Therefore, when grouting wells system is expanded and constructed and groundwater system is established toward channel, it is likely that slopes ending to channel and channel wall will be unstable.

\subsection{Creating waterfall in channel direction}

Erosion will occur intensively at any point of channel which water has turbulent flow and the flow is critical. With regard to the material, we can attempt to intensify the regressive erosion by creating different waterfalls. Fig. 13 shows regressive erosion in a desirable layering of soil. In this figure, one sand layer has been considered between two clay viscous layers. This layer helps expedite regressive erosion to great extent. Rotational flow in water slide from waterfall causes more rapid flushing and erosion of sand than that of clay and sand middle layer erosion causes destruction of the upper layer. Generally, waterfall in the direction is effective on efficiency of the operation in ascending direction.

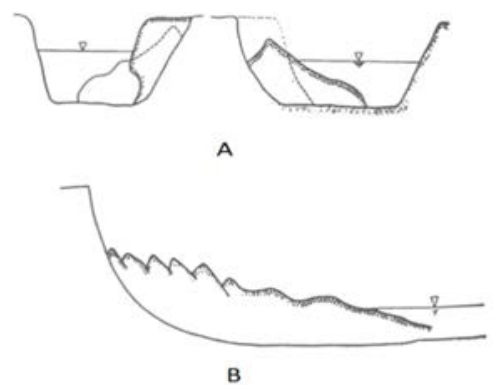

Figure 12: Falling walls in regressive channels. (a) Falling walls in consolidated clay; (b) Falling walls in unconsolidated clay.

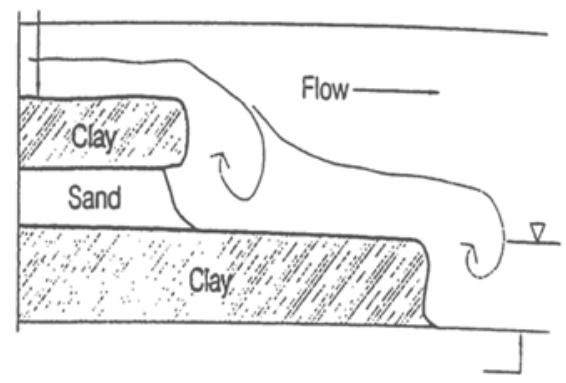

Figure 13: Regressive process. 


\section{CONCLUSIONS}

1. By executing complementary flushing operations which are composed of flushing operations and sediments diversion method, we can increase efficiency of the flushing operations.

2. Dams reservoirs flushing through creation of regressive erosion is an ideal method for transferring the accumulated sediments in reservoir near dam valves and discharging them to downstream of the dam.

3. The presented theory for regressive erosion and volume of the displaced deposit in this way, has high precision, and we can estimate results obtained from these operations with the help of mentioned theories.

4. Difference in theoretical and actual values of the results is due to the applied hypotheses in the mentioned theory. Among such hypotheses, we can refer to some cases, such as sedimentary layers' homogeneity hypothesis, slide of walls which has been considered only due to instability of gables due to increase of height (without consideration of toe erosion of walls).

5. By studying the effect of different parameters on regressive erosion and volume of the displaced sediments, we can say that parameters such as internal friction angle and special weight of sediments have negative effects on volume of sediment and other parameters such as longitudinal slope of channels has positive effect.

6. In some cases, there is clear difference between theoretical and actual values in a time interval resulting from hard sedimentary layers in sediments layering.

7. The mentioned theories in this method, have been studied for practical state, resulting from lack of other states because it has been put into practice only for three times in our country. Then, it is likely that we will solve some problems by studying other states.

\section{REFERENCES}

[1] Ji, U., Julien, P.Y. \& Park, S.K., Sediment Flushing at the Nakdong River Estuary Barrage, p. 14, 2011. 10.1061/(ASCE)HY.1943-7900.0000395.

[2] Andres Brandt, S., Reservoir Desiltation by Means of Hydraulic Flushing, pp. 391-407, 2000.

[3] Sefid-roud Dam Flushing Committee, Report of Sefid-roud Dam Flushing OperationsShahrood Bank, 1988.

[4] Chow, V.T., Open-channel Hydraulics, 1959.

[5] Julien, P.Y., Erosion and Sedimentation, 2010.

[6] Shafaei Bajestan, M., Sediments hydraulics, 2nd ed., 1999.

[7] Leo, C. \& Van Rijn, Principle of Sediment Transport in Rivers, Estuaries and Coastal Seas. Delf Hydraulics, The Netherlands, 1993.

[8] Das, B.M., Principles of Geotechnical Engineering, 2, p. 169.

[9] Gilan Regional Water Organization, Sefid-roud Dam Flushing Operations Report, 2001. 